\title{
John E. Roemer, President-elect of the Society for Social Choice and Welfare 2008-2009, President 2010-2011
}

\section{Marc Fleurbaey ${ }^{1}$}

Published online: 17 November 2017

(C) Springer-Verlag GmbH Germany, part of Springer Nature 2017

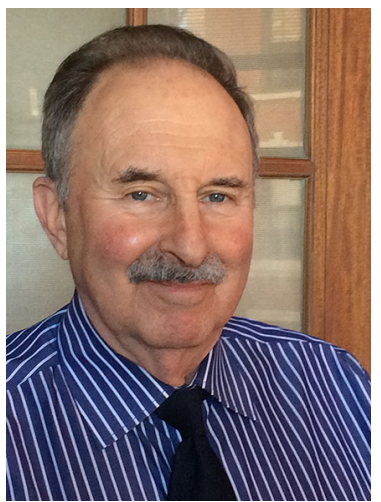

This special issue is in honor of John Roemer, in recognition of his seminal contributions to the theoretical and empirical analysis of societal mechanisms and welfare issues.

Marc Fleurbaey

mfleurba@princeton.edu

1 Woodrow Wilson School, Princeton University, Princeton, USA 